this previous role has deeply changed in an unthinkable way, where women have the possibility to actively participate in areas that involve decision-making and conducting teams. Furthermore, a development must be done to prevent actions of how the occupational risks inherent of this new function will impact, taking into account the primary role of women within the family, helping to make both tasks possible.

Methods An analysis of the assignments performed by women within the Armed Forces of Argentina was carried out during the last 20 years. The main objective of this study was to examinate the physical and psychological impacts these new tasks had on women.

Results Although the statistics available are quite limited, it must be observed that nearly $40 \%$ of the population analysed showed psychic manifestations such as high pressure and family problems, and 20\% have had physical manifestations just as their endocrine system (altered menstrual rhythm, thyroid disorders, infertility, among others.), or cardiac or gastrointestinal issues like arterial hypertension, arrhythmias, irritable colon, and gastritis.

Conclusion To conclude with, it must be said that changes are relatively recent and statistics available are limited. However, the observed data showed that a remarkable emphasis should be placed on the development of a Preventive Program held by the Occupational Health Services of the Armed Forces to identify an early and effective way of the signs and symptoms that show alterations in the health of women workers, which will result from not being treated in time, causing in most of the cases a detriment of their health and a poor standard of living.

\section{FACTORS BASED ON LENGTH OF STAY RELATED TO STRESS RESPONSE OF JAPANESE SPOUSES ACCOMPANYING HUSBANDS POSTED OVERSEAS}

${ }^{1} \mathrm{M}$ Aoyagi ${ }^{*},{ }^{2} \mathrm{Y}$ Takayama, ${ }^{3} \mathrm{M}$ Taga, ${ }^{4} \mathrm{~K}$ Namikawa. ${ }^{1}$ International University of Health and Welfare, Odawara kanagawa, Japan; ${ }^{2}$ International University of Health and Welfare, Narita Chiba, Japan; ${ }^{3}$ Hokkaido Bunkyo University, Eniwa Hokkaido, Japan; ${ }^{4}$ Kawasaki University of Medical Welfare, Kurashiki Okayama, Japan

\subsection{6/oemed-2018-ICOHabstracts. 1516}

Introduction It is often reported that spouses accompanying husband posted overseas suffer from depression and husbands end up returning to Japan with spouses. Although previous studies have confirmed that spousal stress response and selfesteem depend on the length of stay, the presence/absence of children, language barriers, no studies have reported on the associations with these factors based on length of stay.

Objective The purpose of this study is to elucidate the relationship between spousal stress response and presence/absence of children and language barriers, based on length of stay by comparing their status before and after moving overseas.

Method An internet survey was conducted with spouses in December $2016(n=123)$. A multiple regression analysis and multi-population analysis were performed with stress response and self-esteem scores as dependent variables, and length of stay and presence/absence of children (Model 1), language barrier (Model 2) as independent variables.

Results In Model 1, for spouses who had moved overseas less than 1.5 years, presence/absence of children was related to 'impatient feeling,' 'feelings of fatigue,' 'feelings of anxiety,' 'depressed mode,' 'physical complaints,' and 'self-esteem.' In Model 2, 'physical complaints,' 'feelings of fatigue,' and 'feelings of irritation' were found to be related to presence/absence of children in spouses who had moved overseas less than 1.5 years. Moreover, 'depressed mode' and 'feelings of anxiety' were found to be related to presence/absence of children and language barriers. No factors were related to stress response and self-esteem in spouses prior to moving overseas or between 1.5-3.0 years after moving overseas.

Conclusion Stress response after moving overseas was found to be stronger in spouses with a stay of less than 1.5 years, who had children and faced a language barrier. The results suggest the necessity for early support after moving overseas

\section{RELATIONSHIP BETWEEN WORK-FAMILY CONFLICT AND EMOTIONAL MENTAL DISORDER AMONG FEMALE NURSES AT UNIVERSITY-BASED TERTIARY GENERAL HOSPITAL IN JAKARTA}

Fitriani Dewi Yunia*, Hardjono Indra, Soemarko Dewi Sumaryani. Occupational Medicine Program, Faculty of Medicine, Universitas Indonesia, Jakarta, Indonesia

\subsection{6/oemed-2018-ICOHabstracts. 1517}

Introduction Emotional mental disorder is a state of psychological distress that, if not handled properly, can lead to severe mental disorders and disabilities. One potential psychosocial hazard thought to be related to mental health disorders is the work-family conflict. Women who undertake dual roles, as housewives and workers, may potentially experience workfamily conflict. The objectives of this research were to determine the prevalence of emotional mental disorder among female nurses in the university-based tertiary general hospital in Central Jakarta in 2016 and to determine its relationship with work-family conflict.

Methods This was a cross-sectional study by looking for the relationship between the work-family conflict, individual factors and work factors with emotional mental disorder. The instruments used in this study were work-family conflict questionnaire and SRQ 20. The study population was 264 randomly chosen female nurses who were working at universitybased tertiary General hospital in Central Jakarta.

Result The prevalence of emotional mental disorder among female nurses was $23.5 \%$ with somatoform disorder as the most frequent disorders. The prevalence of work-family conflict was $45,1 \%$, which $63 \%$ of them experiencing time-based conflict. The most dominant factors associated with emotional mental disorder were work-family conflict (OR 2.59, 95\% CI: 1.44 to $4.65, \mathrm{p}<0.001$ ) and level of education (OR 0.07, 95\% CI: 0.01 to 0.62 , p:0.010).

Conclusion Compare with the previous results from 1998, the prevalence of mental-emotional disorders among female nurses has increased from $17.7 \%$ to $23.5 \%$ in 2016 . Female nurses who have work-family conflicts are 2.59 times higher risk of experiencing emotional mental disorders than nurses without work-family conflicts. It is urgent to develop a prevention program to protect female nurses from adverse health effect which can lead to decrease in productivity. 